\title{
Seroprevalence of transfusion-transmissible infections among blood donors at National Blood Transfusion Service, Eritrea: a seven- year retrospective study
}

Nejat Siraj ${ }^{1}$, Oliver Okoth Achila ${ }^{1 *} \mathbb{D}$, John Issac ${ }^{1}$, Efrem Menghisteab ${ }^{1}$, Maedn Hailemariam ${ }^{1}$, Semere Hagos ${ }^{1}$, Yosan Gebremeskel ${ }^{1}$ and Daniel Tesfamichael ${ }^{2}$

\begin{abstract}
Background: Blood transfusion is associated with several risks particularly exposure to blood transfusion-transmissible infections (TTI), including: Hepatitis B virus (HBV), Hepatitis C virus (HCV), Human immunodeficiency virus (HIV) and Syphilis, among others. The threat posed by these blood-borne pathogens is disproportionately high in Sub-Saharan Africa (SSA). This fact underscores the need for continuous surveillance of TTls in the region. Therefore, the study objectives were to evaluate the prevalence of TTls and donor characteristics associated with positivity for TTls at the National Blood Transfusion Center (NBTC) in Asmara, Eritrea.
\end{abstract}

Methods: A retrospective analysis of blood donors' records covering the period from January 2010 to December 2016 was undertaken. The records were analyzed to evaluate the annualised cumulative prevalence of TTIs. Chi-square test $\left(x^{2}\right)$ or Fisher's exact test was used to evaluate the relationship between serological positivity and particular donor characteristics. Logistic regression was fitted to identify factors associated with cumulative TTls positivity. A P-value $<0.05$ was considered statistically significant.

Result: A total of 60,236 consecutive blood donors were screened between 2010 and 2016. At least 3.6\% of donated blood was positive for at least one $\mathrm{TI}$ and $0.1 \%$ showed evidence of multiple infections. The seroprevalence of HBV, HCV, HIV, syphilis and co-infection was 2.0, $0.7,0.3$ and $0.6 \%$, respectively. Sex, type of donor and region were associated with TTI positivity. Except for donation frequency, there was a significant relationship $(P<0.005)$ between HBV, HCV, HIV and syphilis sero-positivity and other donor characteristics evaluated in the study.

Conclusion: The result demonstrates that Eritrea has relatively low TTl prevalence compared to other countries in Sub-Saharan Africa. However, the prevalence, particularly that of HCV, increased significantly in 2016. Enhancing donor screening and additional research utilizing nucleic acid based techniques should therefore be prioritized.

Keywords: Prevalence, Blood transfusion, Transfusion transmitted infection, National Blood Transfusion Service

\footnotetext{
* Correspondence: oliverachila@gmail.com

'Department of Clinical Laboratory Science, Asmara College of Health

Sciences, P.O. Box 8566, Asmara, Eritrea

Full list of author information is available at the end of the article
}

(c) The Author(s). 2018 Open Access This article is distributed under the terms of the Creative Commons Attribution 4.0 International License (http://creativecommons.org/licenses/by/4.0/), which permits unrestricted use, distribution, and reproduction in any medium, provided you give appropriate credit to the original author(s) and the source, provide a link to the Creative Commons license, and indicate if changes were made. The Creative Commons Public Domain Dedication waiver (http://creativecommons.org/publicdomain/zero/1.0/) applies to the data made available in this article, unless otherwise stated. 


\section{Background}

Blood transfusion is an important therapeutic intervention that has a critical role in patient management [1]. Nonetheless, availability of safe blood products is still a significant public health concern in Sub-Saharan Africa (SSA). This phenomenon is driven by a range of overarching factors, including endemicity of infections associated with anemia, high prevalence of sickle cell anemia, blood loss linked to accidents, surgical and/or obstetrical emergencies and malnutrition, among others [2]. Despite the existence of World Health Organization (WHO) approved national hemovigilance protocols in most countries in the region, blood transfusion continues to carry a certain margin of risk for both patients and healthcare workers [3]. Hypersensitivity reactions and direct or residual risk associated with a spectrum of transfusion-transmissible infections (TTI), including Human Immunodeficiency virus (HIV), Hepatitis B virus (HBV), Hepatitis C virus (HCV) and Syphilis-causing Treponema palladium (T. pallidum), are the major concerns.

In particular, estimates from a previous multicenter study reported that the post-transfusion risk of HIV infection ranges between 1 in 25,600 and 1 in 90,200 [4]. According to some studies, an estimated 25\% of blood units donated in Francophone SSA is contaminated with markers of blood-borne pathogens [4]. Others have noted that the widespread use of serological tests and possible misclassification of TTI acquired infections in the region may lead to under-reporting of risks $[5,6]$. Overall, the reported proportions of TTIs in SSA are much higher than in industrialised countries [2]. The enhanced odds of acquiring TTIs in the region has been attributed to several challenges, including poor quality test kits and/or unreliable supply of test kits, sub-optimal quality assurance (QA) systems in many centers, shortages of trained laboratory staff, inability to detect recently infected subjects, absence of physical or chemical treatment of blood products [5]. The preponderance of replacement donors (RD) - family members or friends of the patient; as opposed to voluntary non-remunerated blood donors (VNRBD) and the high prevalence of blood-borne infections in the general population in the region has also been linked to the observed TTI associated risk [5].

To reduce TTI-associated risk in SSA, experts have proposed a three-pronged strategy, including improvements in blood donor selection algorithms, more effective TTI detection techniques and chemical and physical treatment of blood products [4]. The latter two strategies are of limited relevance in SSA with the exception of a select number of countries. At present, optimisation of blood donor selection premised on deferral of high-risk prospective donors remains the primary strategy to reduce risk [2]. This strategy emphasizes the need for continuous monitoring of, and reporting on, TTIs. Evaluation of trends in the prevalence of TTIs is not only essential for the assessment of blood safety or the effectiveness of the blood safety strategies; they can also provide an estimate of the epidemiology of sexually-transmitted infections (STI) in the general population [3].

Despite the well recognised importance of studying TTI epidemiology, published information on TTIs burden in SSA is scant [7]. In Eritrea for instance, the last published study on TTIs was conducted in 2009 [8]. This study indicated that the prevalence of TTI markers were $0.18,2.58,0.57$, and $0.49 \%$ for HIV, HBV, HCV and Syphilis, respectively [8]. The scenario may have changed in the interim by virtue of changes in migration flows and urbanization, among others. More importantly, the study had several limitations. For instance, the researchers did not report on the relationship between prevalence of TTIs and associated donor characteristics such as sex, region of residence or age. Therefore, this study not only provides updated information on the prevalence of TTIs and associated factors in Eritrea; it is also more comprehensive given the larger sample size, the expanded number of socio-demographic factors and the longer study duration (7 years).

\section{Methods \\ Study area}

The data was extracted from the National Blood Transfusion Service (NBTS) database. NBTS is the only blood bank in Asmara, the capital city of Eritrea. The facility provides TTI-tested blood and blood products for about 20 referral hospitals in the country [8]. The center has several departments, sections and sub-sections. It comprises of Donor Clinic section, Laboratory section (sub-sections: TTI, Immunohematology and Component Preparation Sections), Quality Management and Data Management sections.

Donors at the facility are predominantly VNRBD and blood units were collected during blood donation campaigns. All the assays conducted by the TTI sub-section to test for HIV, HBV, HCV and Syphilis were performed in strict compliance with existing national testing policies and guidelines.

\section{Study design}

A retrospective descriptive study of blood donor data recorded at NBTC from January 2010 to December 2016 was undertaken. The information expropriated from the database included: coded donor ID, age, sex, region/zone of residence, type of donation and frequency of blood donation. The outcome variables were HBV, HCV, HIV, Syphilis seropositivity and overall TTI. 


\section{Study population}

The study population included all blood donors, 60,236 in total, who donated blood to the NBTS from January 2010December 2016. Participants were either VNRBD (54272) or RD (5963). Donors were selected based on a pre-set criterion which particularized age (16-65 years), weight (>50 kg) and medical history as per NBTS protocol.

\section{Screening methods}

The NBTS-TTI screening department used the following assays: HBsAg (SD HBs Ag ELISA 3.0), HCV (SD HCV ELISA 3.0), Syphilis (MEDIFF TPHA) and HIV testing ELISA-1 (Vironostika ${ }^{\mathrm{R}}$ HIV-1 Plus O Microelisa System) and ELISA - 2 (AccuDiag ${ }^{\text {Tm }}$ HIV 1\&2 Ag/Ab ELISA 4th Generation) or Murex HIV Ag/Ab Combination (ABBOTT Diagnostics Division).

\section{Statistical analysis}

Data retrieved from the NBTS Delphyn Blood Bank Data Management version 7.6.10.0 database was transferred to Excel spread sheet (Microsoft Corp). The data was subsequently cleaned, recoded and analyzed using IBM SPSS Statistics version 20.0 (Armonk, New York, USA). Prevalence of TTI was expressed as the number of seropositive samples per year. Prevalence of anti-HIV, HBsAg, anti-HCV and anti-TP were expressed in percentages per year for specific donor characteristics. Pearson Chi-squire $\left(\chi^{2}\right)$ test or Fisher's exact test was used to evaluate the relationship between categorical variants. Chi-square trend test (Linear-by-Linear association) was applied to examine year-by-year variation in trends. Multivariable binary logistic regression was used to evaluate the relationship between TTI (dependent variable) and the influencing factors (sex, donor type and region of residence). A $p$ - value $<0.05$ was considered statistically significant.

\section{Ethics approval}

Ethical clearance was obtained from Asmara College of Health Science (ACHS) Research Ethical Committee and Eritrean Ministry of Health Research Ethical Committee. Additional approval was obtained from NBTS director. The study utilized previously collected data and no participants were involved at any stage. To guarantee donor confidentiality, donors were anonymized via de-identification (through the use of codes). The process of delinking donor identities and donation units was undertaken exclusively by a data specialist from NBTS. The need to obtain consent from donors was waived by the Eritrean Ministry of Health Research Ethical Committee.

\section{Result}

Socio-demographic characteristics of the donors

A total of 60,236 blood samples donated to the NBTS from January 2010 to December 2016 were retrieved and analyzed for TTIs. The characteristics of the study population are shown in Table 1. Overall, 66.4\% of the donors were males and $33.6 \%$ were females. Their ages (in years) ranged from 16 to 54 . The age grouping spanning 18 24 years constituted the highest proportion of donors $(47.09 \%)$ followed by the age group 25-44 years (24.77\%). A majority of the study participants were VNRBD (90.1\%) with RD accounting for the remaining proportion, 9.9\%. Among the donors, 19,816 (32.9\%) were first time donors, 17,169 (28.5\%) were second time donors and $38.6 \%$ had donated blood more than two times. Further, $46.2 \%$ of the donors had type $\mathrm{O}$ blood group, $25.6 \%$ had type B, $23.1 \%$ had type A and $5.1 \%$ had type $\mathrm{AB}$. In addition to this, $90.6 \%$ of the donors were $\mathrm{Rh}$ positive while 9.4 were $\mathrm{Rh}$ negative.

\section{Seroprevalence of TTI among the donors}

The TTI results of the 60,236 donations are summarized in Table 2. Among the donors, 3.7\% tested positive for at least one TTI. The overall positivity rates of HBV, HCV, HIV, and Syphilis were 2.0, 0.7, 0.3, 0.6 and 0.07\%, respectively.

The most prevalent type of TTI throughout the 7 years was HBV. The proportion of donors infected with at least one TTI was 3.6 and $0.1 \%$ had multiple infections (Maximum $=3$ ). The frequency of TTIs was comparatively higher in 2016 (4.87\%) and lowest in 2010 (2.8\%). The concurrent infection with the highest frequency was HBV-Syphilis. Over the 7-year period, Chi-squire trend test demonstrated a significant increase $(p<0.00)$ in TTI trends from 2013 (3.2\%) to 2016 (4.6\%).

Seropositivity of TTI within specific socio-demographic categories, including sex, age and region of residence were evaluated. Table 3. According to our data, male donors had a significantly higher frequency of TTIs compared to female donors $(4.0 \%$ versus $2.97 \%, p<0.00)$. In particular, male donors had comparatively higher frequencies of HBV ( $2.2 \%$ versus $1.5 \%, p<0.00)$, HCV $(0.8 \%$ versus $0.6 \%$, $p<0.026)$ and syphilis $(0.7 \%$ versus $0.4 \%, p<0.00)$. In contrast, female donors had a marginally higher frequency of HIV compared to male donors $(0.4 \%$ versus $0.3 \%, p<$ $0.005)$. Mixed infections (MI) were only observed in male donors $(0.09 \%)(p<0.05)$.

A statistically significant association was also observed between age categories and TTI seropositivity $(p<0.00)$. The data shows that the frequency of TTI among donors within $45-64,25-44,18-24$ and 16-17 years of age were $5.1,4.1,2.9$ and $4.4 \%$, respectively. In particular, TTI positivity was higher in donors above 45 years of age $(5.1 \%)$ and donors below 17 years of age (4.4\%). Additionally, a significant association was observed between age categories and evaluated TTIs $(p<0.05)$. Markers for HBV and HCV were more prevalent in donors below 17 years $(2.6 \%)$ of age and lowest in donors 
Table 1 Socio-Demographic characteristics of blood donors who donated blood to the NBTS from January 2010 to December 2016

\begin{tabular}{|c|c|c|c|}
\hline \multicolumn{2}{|l|}{ Donor Characteristic } & \multirow{2}{*}{$\frac{\text { Number }(\mathrm{N})}{39,978}$} & \multirow{2}{*}{$\begin{array}{l}\text { Percentage (\%) } \\
66.4\end{array}$} \\
\hline Sex & Male & & \\
\hline & Female & 20,258 & 33.6 \\
\hline Total & & 60,236 & 100 \\
\hline \multirow[t]{4}{*}{ Age } & $16-17$ & 12,666 & 21.0 \\
\hline & $18-24$ & 28,364 & 47.1 \\
\hline & $25-44$ & 14,922 & 24.8 \\
\hline & $45-64$ & 4276 & 7.1 \\
\hline Total & & 60,236 & 100 \\
\hline \multirow[t]{6}{*}{ Region } & Maekel & 46,420 & 77.06 \\
\hline & Debub & 8860 & 14.71 \\
\hline & Anseba & 2268 & 3.77 \\
\hline & Northern Red Sea & 1435 & 2.38 \\
\hline & Gash Barka & 1002 & 1.66 \\
\hline & Southern Red Sea & 251 & 0.42 \\
\hline Total & & 60,236 & 100 \\
\hline \multirow[t]{2}{*}{ Donor Type } & VNRBD & 54,264 & 90.1 \\
\hline & Replacement Donors & 5972 & 9.9 \\
\hline Total & & 60,236 & 100 \\
\hline \multirow[t]{4}{*}{ Donation Frequency } & First time & 19,816 & 32.9 \\
\hline & Second time & 17,169 & 28.5 \\
\hline & Third time & 8668 & 14.4 \\
\hline & Four and above & 14,583 & 24.2 \\
\hline Total & & 60,236 & 100 \\
\hline \multirow[t]{4}{*}{ Blood Type } & O & 27,841 & 46.2 \\
\hline & B & 15,400 & 25.6 \\
\hline & A & 13,917 & 23.1 \\
\hline & $A B$ & 3078 & 5.1 \\
\hline Total & & 60,236 & 100 \\
\hline \multirow[t]{2}{*}{ RH Type } & RH Positive & 54,553 & 90.6 \\
\hline & RH Negative & 5683 & 9.4 \\
\hline Total & & 60,236 & 100 \\
\hline
\end{tabular}

VNRBD Voluntary non replacement blood donors

between 18 and 24 years of age (1.6\%). In contrast, the frequency of anti - T. pallidum antibodies was higher in donors above 45 years (2\%) and lowest in donors between 18 and 24 years $(0.3 \%)$.

Regionally, donors from Gash-Barka region had the highest rate of infection (9.5\%) and donors from Maekel zone had the lowest TTI cases (3.1\%), $p<0.00$. Except for HIV, regional variation in the frequency of specific TTIs was observed $(p<0.00)$. Donors from Gash-Barka had the highest frequency of $\mathrm{HBV}$ (5.1\%), anti-T. pallidum markers $(2.4 \%)$ and co-infections $(0.5 \%)$ compared to the other regions. Additionally, frequency of $\mathrm{HCV}$ markers was significantly higher in Anseba (1.5\%), nearly as high in Gash-Barka (1.4\%) and lowest in Maekel (0.6\%), $p<0.000$.
In this study, RD donors had a higher frequency of TTI compared to VNRBD $(6.9 \%$ versus $3.4 \%$, $p<0.000)$. In particular, the prevalence of TTI markers was significantly higher in RD compared to VNRBD: (3.6\% versus $1.9 \%, p<0.000$ for HBV), ( $1.0 \%$ versus $0.7 \%, p<0.006$ for $\mathrm{HCV}),(0.6 \%$ versus $0.3 \%, p<0.000$ for $\mathrm{HIV})$ and $(1.7 \%$ versus $0.5 \%$, $p<0.000$ for HIV. In addition, the frequency of coïnfections was significantly higher in RD (0.2\%), $p<0.007$. Among all donors, the prevalence of TTIs was $10.8 \%$ for first time donors, $0.16 \%$ for second time donors, $0.53 \%$ third time donors and $0.021 \%$ for donors who had donated blood more than three times $(p<0.000)$. Table 4 . 
Table 2 Positivity rate Transfusion Transmitted Infections (TTI) among the donors by year (January 2010 - Dec 2016)

\begin{tabular}{|c|c|c|c|c|c|c|c|}
\hline Year & Donations & Anti-HBsAg+ No (\%) & Anti-HCV+ No (\%) & Anti-HIV No (\%) & Anti -TP+ No (\%) & MI No (\%) & Total TTI+ No (\%, \\
\hline 2010 & 9977 & $228(2.3)$ & $33(0.3)$ & $37(0.4)$ & $67(0.7)$ & $5(0.05)$ & $370(3.7)$ \\
\hline 2011 & 10,080 & $178(1.8)$ & $54(0.5)$ & $29(0.3)$ & $91(0.9)$ & $8(0.08)$ & 360 (3.6) \\
\hline 2012 & 9219 & $156(1.7)$ & $31(0.3)$ & $33(0.4)$ & $70(0.8)$ & $5(0.05)$ & $295(3.2)$ \\
\hline 2013 & 8661 & $181(2.1)$ & $63(0.7)$ & $26(0.3)$ & $35(0.4)$ & $8(0.09)$ & $313(3.6)$ \\
\hline 2014 & 8051 & $177(2.2)$ & $64(0.8)$ & $21(0.3)$ & $36(0.4)$ & $4(0.05)$ & $302(3.8)$ \\
\hline 2015 & 7006 & $159(2.3)$ & $42(0.6)$ & $16(0.2)$ & $21(0.3)$ & $6(0.09)$ & $244(3.5)$ \\
\hline 2016 & 7242 & $124(1.7)$ & $155(2.1)$ & $20(0.3)$ & $31(0.4)$ & $6(0.08)$ & $336(4.6)$ \\
\hline$P$ - value & & 0.004 & 0.000 & 0.613 & 0.000 & 0.864 & 0.000 \\
\hline Total & 60,236 & $1203(2.0)$ & $442(0.7)$ & $182(0.3)$ & $351(0.6)$ & $42(0.07)$ & $2220(3.7)$ \\
\hline
\end{tabular}

$P$-value, Pearson Chi-square test for statistical difference in the distribution within each group, $M I$ Multiple Infections

Multivariate logistic regression analysis was undertaken to determine the donor characteristics and association to TTI. In this analysis, male donors $(\mathrm{AOR}=0.741$; 95\% CI: $0.672,0.816)$ were less likely to be seropositive compared to female donors. Further, VNRBD (AOR = 2.103 95\% CI: $1.880-2.351$ ) were more likely to be seropositive for TTIs compared to RD. Donors from Gash-Barka (AOR $=0.475,95 \%$ CI, 0.256, 0.882) less likely to be seropositive for TTI. Table 5 .

\section{Discussion}

Eritrea faces critical challenges in blood safety and availability. The high frequency of blood borne viruses and other infectious diseases, including HIV, HBV, HCV and syphilis continue to be a major concern. Although epidemiological reports published in recent years indicate that significant progress has been made in countries where WHO national hemovigilance protocols have been implemented; risk of TTIs is still an issue in Eritrea. Therefore, monitoring prevalence trends of a spectrum of TTIs in donor population remains a valuable index for evaluating the effectives of existing intervention strategies.

In this study, we established that the overall cumulative frequency of TTI markers in donated blood was $3.7 \%$. The finding compares favorably to a previous study in Eritrea which reported a prevalence of $(3.8 \%)$ [8]. However, it is lower than the findings from other multicenter and local studies in SSA. For instance,

Table 3 Positivity rate of transfusion - transmissible infections by sex, age group and region of residence of the donors

\begin{tabular}{|c|c|c|c|c|c|c|c|}
\hline Donor Characteristic & No of Donors (N) & Positive No (\%) & $\mathrm{HBsAg}+\mathrm{No}(\%)$ & Anti-HCV+ No (\%) & Anti - HIV+ No (\%) & Anti -TP+ No (\%) & MI No (\%) \\
\hline \multicolumn{8}{|l|}{ Sex } \\
\hline Male & 39,978 & $1619(4.0)$ & $892(2.2)$ & $313(0.8)$ & $104(0.26)$ & $275(0.7)$ & $35(0.09)$ \\
\hline Female & 20,258 & $601(2.97)$ & $311(1.5)$ & $129(0.6)$ & $78(0.39)$ & $76(0.4)$ & $7(0.0)$ \\
\hline$P$-value & & $0.000^{*}$ & $0.000^{*}$ & $0.026^{*}$ & $0.005^{*}$ & $0.000^{*}$ & $0.015^{*}$ \\
\hline \multicolumn{8}{|l|}{ Age Group } \\
\hline $16-17$ & 12,666 & $566(4.4)$ & 331 (2.6) & $115(0.9)$ & $53(0.4)$ & $61(0.5)$ & $6(0.0)$ \\
\hline $18-24$ & 28,364 & $817(2.9)$ & 467 (1.6) & $181(0.6)$ & $57(0.2)$ & $94(0.3)$ & $18(0.1)$ \\
\hline $25-44$ & 14,922 & $614(4.1)$ & $322(2.2)$ & $114(0.8)$ & $54(0.4)$ & $112(0.8)$ & $12(0.1)$ \\
\hline $45-64$ & 4276 & $223(5.1)$ & $83(1.9)$ & $32(0.7)$ & $18(0.4)$ & $84(2.0)$ & $6(0.1)$ \\
\hline$P$-value & & 0.000 & 0.000 & 0.000 & 0.001 & 0.000 & 0.357 \\
\hline \multicolumn{8}{|l|}{ Region of Residence } \\
\hline Maekel & 46,420 & $1449(3.1)$ & 731 (1.6) & $291(0.6)$ & $145(0.3)$ & $258(0.6)$ & $24(0.1)$ \\
\hline Debub & 8860 & $455(5.1)$ & $285(3.2)$ & $87(1.0)$ & $26(0.3)$ & $49(0.6)$ & $8(0.1)$ \\
\hline Gash-Barka & 1002 & $95(9.5)$ & $51(5.1)$ & $14(1.4)$ & $1(0.1)$ & $24(2.4)$ & $5(0.5)$ \\
\hline Anseba & 2268 & $120(5.3)$ & $71(3.1)$ & $35(1.5)$ & $5(0.2)$ & $6(0.3)$ & $3(0.1)$ \\
\hline North Red Sea & 1436 & $89(6.2)$ & $57(4.0)$ & $13(0.9)$ & $4(0.3)$ & $13(0.9)$ & $2(0.1)$ \\
\hline South Red Sea & 251 & $12(4.8)$ & $8(3.2)$ & $2(0.8)$ & $1(0.4)$ & $1(0.4)$ & $0(0.0)$ \\
\hline$P$-value & & 0.000 & 0.000 & 0.000 & 0.828 & 0.000 & 0.000 \\
\hline
\end{tabular}

$P$-value, Pearson Chi-square test and Fishers exact test $\left(^{*}\right)$ for statistical difference in the distribution within each group, MI Multiple Infections 
Table 4 Positivity rate of transfusion - transmissible infections (TTI) by donor type and donation frequency of the donors

\begin{tabular}{|c|c|c|c|c|c|c|c|}
\hline Variables & No of Donor & Positive No (\%) & $\mathrm{HBsAg}+\mathrm{No}(\%)$ & Anti-HCV+ No (\%) & Anti - HIV+ No (\%) & Anti -TP+ No (\%) & MI No (\%) \\
\hline \multicolumn{8}{|l|}{ Donor Type } \\
\hline VNRBD & 54,264 & $1808(3.3)$ & $1031(1.9)$ & $382(0.7)$ & $146(0.3)$ & $249(0.5)$ & $32(0.1)$ \\
\hline Replacement & 5972 & $412(6.9)$ & $214(3.6)$ & $60(1.0)$ & $36(0.6)$ & $102(1.7)$ & $10(0.2)$ \\
\hline$P$-value & & $0.000^{*}$ & $0.000^{*}$ & $0.006^{*}$ & $0.000^{*}$ & $0.000^{*}$ & $0.007^{*}$ \\
\hline \multicolumn{8}{|c|}{ Donation Frequency } \\
\hline First time & 19,816 & $2142(10.8)$ & $1165(5.8)$ & $426(2.2)$ & $172(0.9)$ & $339(1.7)$ & $40(0.2)$ \\
\hline Second time & 17,169 & $29(0.16)$ & $12(0.06)$ & $8(0.05)$ & $3(0.05)$ & $6(0.03)$ & $0(0.0)$ \\
\hline Third time & 8668 & $46(0.53)$ & $25(0.29)$ & $8(0.09)$ & $6(0.07)$ & $5(0.06)$ & $2(0.02)$ \\
\hline Four \& above & 14,583 & $3(0.021)$ & $1(0.007)$ & $0(0.0)$ & $1(0.007)$ & $1(0.007)$ & $0(0.0)$ \\
\hline$P$ - value & & 0.000 & 0.048 & 0.572 & 0.240 & 0.561 & 0.548 \\
\hline
\end{tabular}

$P$-value, Pearson Chi-square test and Fishers exact test $\left.{ }^{*}\right)$ for statistical difference in the distribution within each group, MI Multiple Infections. VNRBD Voluntary non-replacement blood donors

previous studies in Ethiopia [3], Mozambique [9], Equatorial New Guinea [10] and Burkina Faso [11] reported a seroprevalence of $6.55,18.7,37.39$ and $24 \%$, respectively. In contrast, lower prevalence was reported in earlier studies undertaken in Namibia (1.4\%) [12] Iran (0.254\%) [13] and China (2.67\%) [14].

Several issues should be noted in the reported results. Of note is the fact the frequency of TTI markers reported in this study are comparatively low. Nevertheless, Chi squire $\left(x^{2}\right)$ trend test demonstrated an increasing trend. However, it should be emphasised that the sharp uptick in the frequency of $\mathrm{HCV}$ in 2016 account for much of the observed trend. Interestingly, significant reduction in the frequency of syphilis and anti-HBV makers was also noted. The lower frequency of TTIs may be attributed to several factors, including the

Table 5 Multivariate Logistic regression model for demographic predictors of $\pi \mathrm{T}$

\begin{tabular}{|c|c|c|}
\hline Catégories & $P$-values & AOR (95\% Cl) \\
\hline \multicolumn{3}{|l|}{ Sex } \\
\hline Female $^{a}$ & & 1 \\
\hline Male & 0.000 & $0.741(0.672-0.816)$ \\
\hline \multicolumn{3}{|l|}{ Type of Donor } \\
\hline Replacement Donor ${ }^{a}$ & & 1 \\
\hline VNRBD & 0.000 & $2.103(1.880-2.351)$ \\
\hline \multicolumn{3}{|l|}{ Region of Residence } \\
\hline Southern Red Sea & & 1 \\
\hline Maekel & 0.192 & $1.475(0.823-2.645)$ \\
\hline Debub & 0.519 & $0.824(0.457-1.485)$ \\
\hline Gash-Barka & 0.018 & $0.475(0.256-0.882)$ \\
\hline Anseba & 0.574 & $0.840(0.456-1.545)$ \\
\hline Northern Red Sea & 0.293 & $0.717(0.386-1.333)$ \\
\hline
\end{tabular}

relatively low prevalence of blood-borne pathogens such as HIV in the general population [15] and more effective pre-donation screening designed to exclude high risk donors and the higher frequency of VNRBD, among others. Another important finding is that the frequency of TTI in RD was comparatively higher (6.9\% versus $3.3 \%$ for VNRBD). A similar finding was reported by researchers working elsewhere [16-18]. In general, RD donors are regarded as a high risk group. This adequately corroborated presumption has been linked to a variety of factors including the possibility that family members and friends are more likely to provide false information on issues that might invite further inquiry thereby limiting the level of protection provided by risk-screening questionnaires [19]. In addition, family members may be at a higher risk for some infection due to a shared exposure to specific predisposing factors or environment, for example, HBV.

Furthermore, the frequency of TTI markers in this study was significantly associated with sex with a higher prevalence reported in male donors. A similar association was reported in a study conducted at the Jijiga Blood Bank, Eastern Ethiopia (11.6\% males versus 3.8\% females) [16]. The higher proportion of male donors presenting with TTI markers may be attributed to behavioral, religious and socio-cultural drivers of high-risk sexual behavior that are typically found in conservative societies. Another plausible explanation of this disproportionate male to female TTI positivity ratio may be related to the fact that females are better diagnosed in Eritrea due to pre-natal care. Thus, a higher proportion of female blood donors may be aware of their seronegative status, at least for some TTIs. A similar suggestion was previously proposed to explain comparable results in a study conducted in Brazil [19]. The frequency of TTI markers was also found to be higher in RD compared to VNRBDs in this study. A higher frequency of 
TTI was also observed in first-time donors. The results provide additional support to the general notion, widespread in blood transfusion literature, that first-time donors constitute a high risk group [2]. This position is premised on the suggestion that these donors have ambiguous motive to donate and have had no previous pre-donation screening for TTIs. Moreover, the possibility of accessing screening for particular TTIs (HIV for instance) may incentivise some individuals to donate blood. Others may be incentivised by the possibility of financial compensation.

The prevalence of TTI markers in donors in the evaluated age categories was also different. This outcome is in line with findings from others studies [14]. The frequency of TTI markers was substantially higher in donors above 45 years and in those below 17 years. Donors within the 18-24 year age grouping had the lowest TTI prevalence. The explanation for the observed pattern may be associated with behavioral characteristics unique to these age categories. Conversely, the finding may indicate that the intervention measures implemented in the country may have disproportionate impact on the disparate age groupings. Regional disparity in TTI prevalence was also observed with donors from Gash-Barka recording generally higher prevalence. This may be ascribed to cultural differences and regional variations in general levels of education, among others.

Although the frequency of TTI reported in this study is nearly similar to that of a previous local study, significant differences pertaining to seroprevalence and trends of particular TTIs was observed. The most dominant type of TTI over the study duration was HBV (2.0\%). The reported prevalence was lower when compared to results obtained from similar studies conducted in the region $[1,7,20]$. Further, the high prevalence of $\mathrm{HBV}$ among blood donors in SSA has been attributed to the high prevalence $[8 \%]$ and endemicity of the virus in the region [2]. A point reflected in estimated transfusion risk models which place HBV above HIV in Africa [2]. These results point to the possibility that the prevalence of HBV in the general population maybe comparatively high. Equally notably is the fact that prevalence of HBV markers exhibited a statistically significant association with sex, age categories, regions and donor type. Behavioural, cultural and socio-economic differences associated with membership to these categories may explain the observed variation. In particular, the high seroprevalence of HBV markers (and HCV) in donors below 17 years of age may be linked to the fact that most young people acquire piercings or tattoos at this age This hypothesis is highly speculative and warrants further investigation.

The overall prevalence of $\mathrm{HCV}$ was $0.7 \%$. This was slightly higher than findings from previously studies from Southern Africa $[9,12]$. Although this value compares favourably to findings from a study in North West Ethiopia [3], the prevalence was lower when compared to studies conducted in Egypt (4.3\%) [21], Tanzania 1.5\% [22], Ethiopia [1] and Sudan 3.4\% [23]. This result corroborates the assertion that $\mathrm{HCV}$ poses less risk to blood transfusion in Southern parts of Africa by virtue of low prevalence [2]. However, it is important to note that the presence of anti-HCV antibodies among apparently healthy blood donors in Eritrea confirms the presence of $\mathrm{HCV}$ in the country. In addition, our data also demonstrated that there has been an upward trend in $\mathrm{HCV}$ prevalence over the years - the sharp uptick in 2016 is particularly noteworthy. Although this finding should raise concern, it should be viewed in light of previous reports which noted that $\mathrm{HCV}$ antibody tests tend to have high false positive misclassification in African populations $[24,25]$. The high frequency of false-positive antibodies (FPA) for $\mathrm{HCV}$ has been associated with infectious agents such as malaria, Schistosoma mansoni, Syphilis, HIV, malnutrition or other chronic infections [24]. Therefore, it's our opinion that in the absence of confirmatory nucleic acid based tests (NAT) for HCV; categorical estimates of the frequency of $\mathrm{HCV}$ among blood donors in this population may be elusive.

According to this study, the prevalence of HIV among blood donors was $0.7 \%$. The proportion is considerably lower compared to other studies conducted elsewhere in Africa $[1,7,10,21,26]$. However, it was higher than the results obtained in Libya $(0.014 \%)$ [27] and Egypt (0.00\%) [28]. The observed prevalence shows consistency with reported HIV seroprevalence in Eritrea [29]. Compared to a previous study, disproportionate HIV prevalence was observed between RD and VNRBD [8]. An association between age grouping and sex was also observed. Higher burden of infection occurred in females and in individuals below 17 years and above 25 years. An explanation for the relatively lower proportion of HIV seroprevalence in males and in donors between 18 and 24 years of age is not apparent. This situation is particularly remarkable given the fact that this is the only infection in which women exhibit a higher burden of disease compared to males. Moreover, Syphilis, a known predisposing factor for HIV, was significantly higher in males.

Treponemal positivity prevalence of $0.6 \%$ was also reported in this study. The observed value is lower compared to studies conducted in the region $[1,10,30]$. The prevalence of syphilis was highest in Ghash-Barka and among individuals aged between 45 and 64 years of age. This finding provides additional support for a recent review which concluded that higher prevalence of $T$. pallidum markers is normally found in elderly donors and in donors with low level of education [31]. Equally notable 
is the fact that Gash-Barka has a significant proportion of pastoralist communities who tend to have low level of education and are hard to reach with health intervention measures.

\section{Limitation of the study}

This study was a retrospective in design. Therefore, we were not able to control, or provide information on, a range of factors which may have had a bearing of the results. For instance, the range of risk factors evaluated in this study was limiting. Indeed, a screening questionnaire customised to the study environment may have provided more insight on the opportunities for optimization of donor selection and testing algorithm from a local standpoint. Another weakness may be associated with intrinsic weakness of the diagnostic test used in this study - use of serological as opposed to nucleic acid based techniques. Therefore, the results reported in this study may underestimate (presence of a window period) or overestimate (high rate of false positivity $\mathrm{HCV}$ ) the frequency of TTIs among donors in this population.

\section{Conclusion}

The overall prevalence of TTIs in Eritrea is comparatively low. This situation may be attributed to several factors, including an effective system for donor recruitment, selection and screening, among others. However, the study demonstrated the fact that the risk of TTIs is still substantial, a problem which is compounded by indicators; reported in this study, which appear to suggest that the frequency of specific TTIs such as HCV have increased marginally over time. According to the study, $\mathrm{HBV}$ followed by $\mathrm{HCV}$, had the highest frequency in Eritrea. The prevalence of the TTIs evaluated in this study was associated with sex, region/zone of residence, type of donor and frequency of donation. In particular, the prevalence of TTI was high among male, RD and donors from Gash Barka region. The relatively high prevalence of TTIs (HBV and $\mathrm{HCV}$, in particular), in donors below 17 years of age is also noteworthy. Therefore, there is an urgent need to investigate the epidemiology of TTIs in Eritrea. This can be achieved through continuous monitoring of the prevalence of TTI-markers in the population via the utilization of contextualised screening questionnaires and the use of NAT methods.

\footnotetext{
Abbreviations

ACHS: Asmara College of Health Science; AOR: Adjusted odds ratio; Cl: Confidence interval; ELISA: Enzyme linked immunosorbent assay; FPA: False-positive antibodies; HBV: Hepatitis B virus; HCV: Hepatitis C virus; HIV: Human immunodeficiency virus; NBTS: National blood transfusion service; NRS: Northern red sea region; RD: Replacement donors; SPSS: Statistical package for social services; SRS: Southern red sea region; TPHA: Treponema Pallidum Hemoagglutination Assay; TTI: Transfusion transmitted infection; VNRBD: Voluntary non-replacement blood donors
}

\section{Acknowledgements}

The authors would like to thank members of the National Blood Transfusion Service (NBTS) for assisting them in the extraction of data from NBTS database.

\section{Funding}

Material support was obtained from Eritrean Ministry of Health and Asmara College of Health (ACHS) Sciences.

\section{Availability of data and materials}

The data used in this study is available from the corresponding author on reasonable request.

\section{Authors' contributions}

NS conceived of the study, participated in the design and drafted the manuscript. OA performed the statistical analysis, re-drafted and edited the manuscript. JI was involved in the proposal development, obtained ethical papers and edited the manuscript. EM, MH, SH and YG conceived of the study, participated in the design and collected the data. DT participated in the design of the research and collected the data. All authors read and approved the final manuscript.

\section{Competing interest}

The authors declare that they have no competing interests.

\section{Ethics approval and consent to participate}

Ethical clearance was obtained from Asmara College of Health Science (ACHS) Research Ethical Committee and Eritrean Ministry of Health Research Ethical Committee. Additional approval was obtained from NBTS director. The study utilized previously collected data and no participants were involved at any stage. To guarantee donor confidentiality, donors were anonymized via de-identification (through the use of codes). The process of delinking donor identities and donation units was undertaken exclusively by a data specialist from NBTS. The need to obtain consent from donors was waived by the Eritrean Ministry of Health Research Ethical Committee.

\section{Publisher's Note}

Springer Nature remains neutral with regard to jurisdictional claims in published maps and institutional affiliations.

\section{Author details}

${ }^{1}$ Department of Clinical Laboratory Science, Asmara College of Health Sciences, P.O. Box 8566, Asmara, Eritrea. ${ }^{2}$ Data Mangement Unit, National Blood Transfusion Service (NBTS), Asmara, Eritrea.

Received: 8 August 2017 Accepted: 30 May 2018

Published online: 07 June 2018

References

1. Arshad A, Borhany M, Anwar N, Naseer I, Ansari I, Boota S, Fatima N, Zaidi $M$, Shamsi T. Prevalence of transfusion transmissible infections in blood donors of Pakistan. BMC Hematol. 2016;16:27. https://doi.org/10.1186/ s12878-016-0068-2.

2. Bloch EM, Vermeulen M, Murphy E. Blood transfusion safety in Africa: a literature review of infectious disease and organizational challenges. Transfus Med Rev. 2012;26(2):164-80.

3. Biadgo B, Shiferaw E, Woldu B, Alene KA, Melku M. Transfusion-transmissible viral infections among blood donors at the North Gondar district blood bank, Northwest Ethiopia: a three year retrospective study. PLoS One. 2017; 12(7):e0180416.

4. Tagny CT, Kouao MD, Touré H, Gargouri J, Fazul AS, Ouattara S, Anani L, Othmani H, Feteke L, Dahourou H, Mbensa GO. Transfusion safety in francophone African countries: an analysis of strategies for the medical selection of blood donors. Transfusion. 2012;52(1):134-43.

5. Osaro E, Charles AT. The challenges of meeting the blood transfusion requirements in sub-Saharan Africa: the need for the development of alternatives to allogenic blood. J Blood Med. 2011;2:7.

6. Moukoko CE, Sack FN, Same EG, Mbanque M, Lehman LGHIV. HBV, HCV and T. Pallidum infections among blood donors and transfusion-related complications among recipients at the Laquintinie hospital in Douala, Cameroon. BMC Hematol. 2014;14(1):5. 
7. Bisetegen FS, Bekele FB, Ageru TA, Wada FW. Transfusion-transmissible infections among voluntary blood donors at Wolaita Sodo University teaching referral hospital, South Ethiopia. Can J Infect Dis Med Microbiol. 2016:2016:15.

8. Fessehaye N, Naik D, Fessehaye T. Transfusion transmitted infections-a retrospective analysis from the National Blood Transfusion Service in Eritrea. Pan Afr Med J. 2011;9(1):1-6. http://www.panafrican-med-journal.com/ content/article/9/40/full/.

9. Stokx J, Gillet P, De Weggheleire A, Casas EC, Maendaenda R, Beulane AJ, Jani IV. Kidane S, Mosse CD, Jacobs J, Bottieau E. Seroprevalence of transfusion-transmissible infections and evaluation of the pre-donation screening performance at the provincial Hospital of Tete, Mozambique. BMC Infect Dis. 2011;11(1):141.

10. Xie DD, Li J, Chen JT, Eyi UM, Matesa RA, Obono MM, Ehapo CS, Yang $L Y$, Yang $H$, Yang $H T$, Lin M. Seroprevalence of human immunodeficiency virus, hepatitis B virus, hepatitis C virus, and Treponema pallidum infections among blood donors on Bioko Island, Equatorial Guinea. PLoS One. 2015;10(10):e0139947.

11. Nagalo BM, Bisseye C, Sanou M, Kienou K, Nebié YK, Kiba A, Dahourou H, Ouattara S, Nikiema JB, Moret R, Zongo JD. Seroprevalence and incidence of transfusion-transmitted infectious diseases among blood donors from regional blood transfusion centres in Burkina Faso, West Africa. J Trop Med. 2012;17(2):247-53.

12. Mavenyengwa RT, Mukesi M, Chipare I, Shoombe E. Prevalence of human immunodeficiency virus, syphilis, hepatitis B and C in blood donations in Namibia. BMC Public Health. 2014;14(1):424

13. Farshadpour F, Taherkhani R, Tajbakhsh S, Tangestani MG, Hajiani G, Sharifi $\mathrm{N}$, Taherkhani S, Nejadbolkheyr A. Prevalence and trends of transfusiontransmissible viral infections among blood donors in south of Iran: an eleven-year retrospective study. PLoS One. 2016;11(6):e0157615.

14. Song Y, Bian Y, Petzold M, Ung C. Prevalence and Trend of major transfusion-transmissible infections among blood donors in western China, 2005 through 2010. PLoS One. 2014;9(4):1-6. https://doi.org/10.1371/journal. pone.0094528

15. Shaikh M, Bhople KS. Seroprevalence of transfusion transmitted infections in blood donors at a rural based tertiary care teaching hospital in India. IOSR J Dent Med Sci (IOSR-JDMS). 2015;14(10):29-32.

16. Mohammed $Y$, Bekele A. Seroprevalence of transfusion transmitted infection among blood donors at Jijiga blood bank, eastern Ethiopia: retrospective 4 years study. BMC Res Notes. 2016;9(1):129.

17. Chaurasia RK, Puja P, Kumar A, Singh P. Pattern of transfusion transmitted infections in blood donors around Bhopal - a 5 years retrospective study. Ann Int Med. 2016;2(6):12-5. https://doi.org/10.21276/aimdr.2016.2.6.PT3.

18. World Health Organization (WHO). Blood Safety Strategy for the African Region Brazzaville, World Health Organization, Regional Office for Africa (WHO AFR /RC51/9 Rev.1). 2002.

19. Sabino EC, Goncalez TT, Carneiro-Proietti AB, Sarr M, Ferreira JE, Sampaio DA, Salles NA, Wright DJ, Custer B. Busch M. HIV prevalence, incidence and residual risk of transmission by transfusions at REDS-II blood centers in Brazil. Transfusion. 2012;52(4):870-9. https://doi.org/10.1111/j.1537-2995. 2011.03344.x.

20. Buseri Fl, Muhibi MA, Jeremiah ZA. Sero-epidemiology of transfusiontransmissible infectious diseases among blood donors in Osogbo, southWest Nigeria. Blood Transfus. 2009;7(4):293.

21. Omran D, Hussein EA, Nagib M. Safety of Blood Transfusion: An Egyptian Study. Infectious Diseases \& Therapy. 2013;2(1):1-4. https://doi.org/10.4172/ 2332-0877.1000124.

22. Matee MI, Magesa PM, Lyamuya EF. Seroprevalence of human immunodeficiency virus, hepatitis B and C viruses and syphilis infections among blood donors at the Muhimbili National Hospital in Dar es salaam, Tanzania. BMC Public health. 2006;6(1):21.

23. Bazie EA, Ali MA, Hamza HB, Magzoub OS, Salih MS, Haroun BE. Seroprevalence of viral transfusion-transmissible infections among blood donors at Kosti teaching hospital, White Nile state/Sudan. Int J Curr Microbiol App Sci. 2015;4(5):1132-8

24. Mullis CE, Laeyendecker O, Reynolds SJ, Ocama P, Quinn J, Boaz I, Gray RH, Kirk GD, DI T, Quinn TC, Staninski L. High frequency of false-positive hepatitis C virus enzyme-linked immunosorbent assay in Rakai, Uganda. Clin Infect Dis. 2013;57(12):1747-50

25. Sakiani S, Koh C, Heller T. Understanding the presence of false-positive antibodies in acute hepatitis. J Infect Dis. 2014;210:1886-9.
26. Akinleye OM, Olaniyan JA, Akintola JO, Okoye CA, Eke CF. Blood safety and prevalence of transfusion transmissible viral infections among blood donors in Lagos, Nigeria. Int J Trop Med. 2013;8(5-6):113-8.

27. Ali MS, Qowaider SR, Moftah SA. Seroprevalence rates of transfusiontransmitted infections among blood donors in northeast of Libya. J Sci Humanit. 2014;19:1-7.

28. Nada HA, Atwa M. Seroprevalence of HBV, HCV, HIV and syphilis markers among blood donors at Suez Canal university hospital blood Bank. J Blood Disord Transfus. 2013;5:177. https://doi.org/10.4172/2155-9864.1000177.

29. UNAIDS. http://www.unaids.org/en/regionscountries/countries/eritrea Accessed on 14 July 2017.

30. Moukoko CE, Sack FN, Same EG, Mbangue M, Lehman LG. HIV, HBV, HCV and T. Pallidum infections among blood donors and transfusion-related complications among recipients at the Laquintinie hospital in Douala, Cameroon. BMC Hematology. 2014;12(14(1)):5.

31. Bekele $\Pi$, Adera GA, Semgne G, Degu BG, Teferi BM, Demelash A, Ali EB, Mekonnon SG, Yonas Y. Seroprevalence and diagnosis of HIV, HBV $\mathrm{HCV}$ and syphilis infections among blood donors. Hum Antibodies. 2017:25(1-2):39-55

\section{Ready to submit your research? Choose BMC and benefit from:}

- fast, convenient online submission

- thorough peer review by experienced researchers in your field

- rapid publication on acceptance

- support for research data, including large and complex data types

- gold Open Access which fosters wider collaboration and increased citations

- maximum visibility for your research: over $100 \mathrm{M}$ website views per year

At BMC, research is always in progress.

Learn more biomedcentral.com/submissions 